$\xi=$ 잘

\title{
Management of chronic periodontitis: an interdisciplinary approach
}

\author{
Sneha Dani ${ }^{1 *}$, Ashwin Prabhu ${ }^{2}$, Savitha AN ${ }^{3}$, Kenneth Tan ${ }^{4}$, Anand Vinod Naik ${ }^{5}$, Charan R Chhatrala ${ }^{6}$ \\ ${ }^{1}$ Sneha Dani MDS (Periodontics), K.L.E Institute of Dental sciences and hospital, Bangalore \\ ${ }^{2}$ Ashwin Prabhu, MDS (Periodontics), K.L.E Institute of Dental sciences and hospital, Bangalore \\ ${ }^{3}$ Savitha AN MDS (Periodontics), Oxford Dental College, Hospital and Research Centre, Bangalore \\ 4 Kenneth Tan MDS (Orthodontics), Oxford dental college, Hospital and Research Centre, Bangalore \\ 5 Anand Vinod Naik, MDS (Orthodontics), Oxford dental college, Hospital and Research Centre, Bangalore \\ 6 Charan R Chhatrala, MDS (Orthodontics), Oxford dental college, Hospital and Research Centre, Bangalore \\ *Corresponding author E-mail: drsnehadani@gmail.com
}

\begin{abstract}
Objective: In recent years, advances in technique as well as a growing public interest in developing and maintaining a healthy and attractive smile, has resulted in a greater understanding of the interrelationships between periodontics and orthodontics. The primary objective of periodontal therapy is to restore and maintain the health and integrity of the attachment apparatus of teeth. In adults, the loss of teeth or periodontal support can result in pathological teeth migration involving either a single tooth or a group of teeth. This may result in the development of a diastema, incisal proclination, rotation with collapse of the posterior occlusion.

Materials and methods: This case report is of a 32 year old female patient who reported with swollen gums, generalized spacing between the teeth and extruded upper anterior tooth. Periodontal therapy followed by fixed orthodontic therapy was planned.

Results: At the end of 2 years a stable healthy periodontium was established that was both functional and esthetic.

Conclusion: Adjunctive orthodontic therapy is often necessary for successful restoration of periodontal health. On the other hand, successful orthodontic treatment will depend on the periodontal preparation before and after treatment and the maintenance of periodontal health throughout all phases of mechano-therapy.
\end{abstract}

Keywords: Adult Orthodontics; Chronic Periodontitis; Dento-Facial Esthetics; Interdisciplinary Treatment; Pathologic Migration

\section{Introduction}

Aesthetic considerations have influenced the management of dental maladies in varying degrees for many years. There is an ever increasing concern for dentofacial esthetics in adult population. The primary motivating factor for seeking orthodontic treatment is dental appearance. [1] (Ngom PI et al. 2006, p. 236). Patient awareness and expectations have increased recently to the point that less than optimal aesthetics is no longer an acceptable outcome. On the same plateau, an essential goal of orthodontic treatment is the long-term stability of the result. For this to be achieved the integrity of the dentogingival junction must be respected, the dental restorations and the periodontium must be in harmony. A predictable, successful outcome can only be expected if complete and accurate diagnosis is obtained and used to generate an appropriate treatment plan and procedure.[2] (Lt Col M Panwar et al. 2010, p. 67)

Advanced periodontal disease is characterized by severe attachment loss, reduced alveolar bone support, tooth mobility and severe gingival recession. Thus periodontal disease and its sequale such as diastema, pathological migration, often lead to functional and esthetic problems either alone or with restorative problems. [3] (Helm S \& Petersen PE 1989, p. 223)

One of the most frequently encountered problems among the adult population is pathologic migration of anterior teeth, which is a common cause of esthetic concern. Pathologic migration is defined as change in tooth position resulting from disruption of the forces that maintain teeth in normal position in relation to their arch. [4] (Kokich VG 2009, p. 856)

This disruption of equilibrium in tooth position may be caused by several etiologic factors which include periodontal attachment loss pressure from inflamed tissues, occlusal factors, oral habits such as tongue thrusting and bruxism, loss of teeth without replacement gingival enlargement and iatrogenic factors.[5] (Martinez-Canut $\mathrm{P}$ \& Carrasquer A 1997, p. 492). These factors if left untreated can lead to progressive periodontal attachment loss and ultimately resulting in tooth loss.

This is a case report of a patient whose main concern was unaesthetically appearing upper front tooth. A combined treatment approach, including both orthodontic and periodontal treatment was performed in order to restore the health and function of teeth and the periodontium. The orthodontic treatment was initiated only after periodontal disease was brought under control. This communication highlights good treatment outcome that can be achieved in a patient with impaired dentofacial aesthetics and advanced periodontal disease. [6] (Kalia S \& Melsen B 2001, p. 191).

\section{Case report}

A 32-year-old female patient reported to the periodontics department with the chief complaint of swollen gingiva in lower anterior region and extruded upper front tooth from past six months. Patient also complained of spacing between her upper front teeth, which gradually increased over a period of time. Patient's main 
concern was to get her teeth realigned as it was very unaesthetic (Figure. 1)

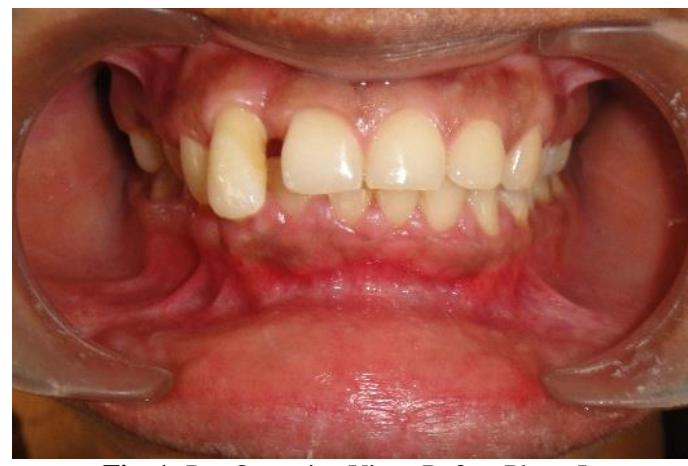

Fig. 1: Pre-Operative View, Before Phase I.

On hard tissue examination, it was found that 12 was extruded and touching the lower lip, 15 was in cross bite. There was a loss of contact between 12 and 11 due to pathologic migration of 12 , causing spacing between the teeth. On the contralateral side, there was an absence of contact between 23 and 24. Periodontal examination revealed sub-gingival deposits that were the cause for the inflammation in the lower gingiva. Furthermore, there were deep periodontal pockets, ranging between 6 to $8 \mathrm{~mm}$, with respect to $12,15,16$ and 36 . Treatment plan included periodontal treatment followed by orthodontic therapy. (Figure. 2, 3)

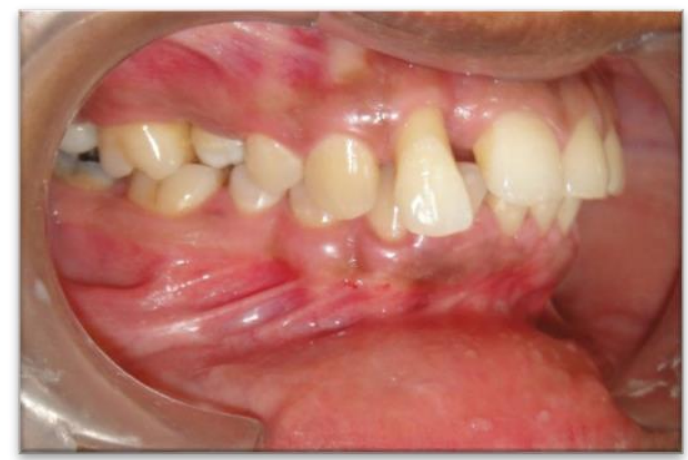

Fig. 2: Extruded 12 and Loss of Contact B/N 11 and 12 .

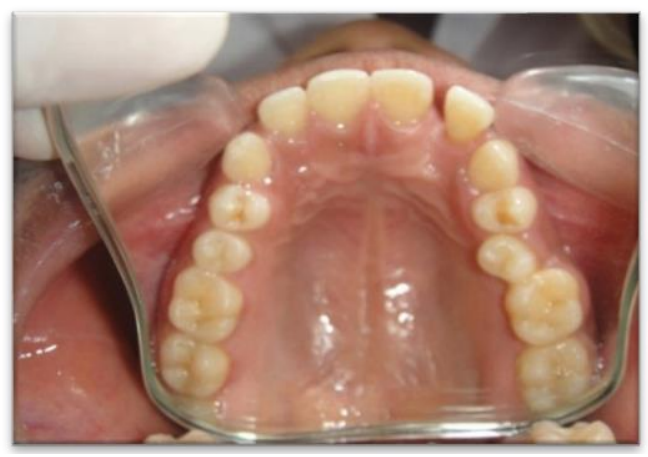

Fig. 3: Cross Bite WRT 15.

Initially, scaling and root planing was performed to eliminate the local factors. Oral hygiene instructions were given, and patient was put on a rigorous maintenance program. The patient was reevaluated after 4-6 weeks to check for any clinical signs of gingival inflammation. Once the inflammation subsided localized periodontal flap surgeries were performed in areas with persisting probing pocket depth. After 6 months, the patient was referred for orthodontic treatment. (Figure 4-8)

\section{Periodontal flap surgery}

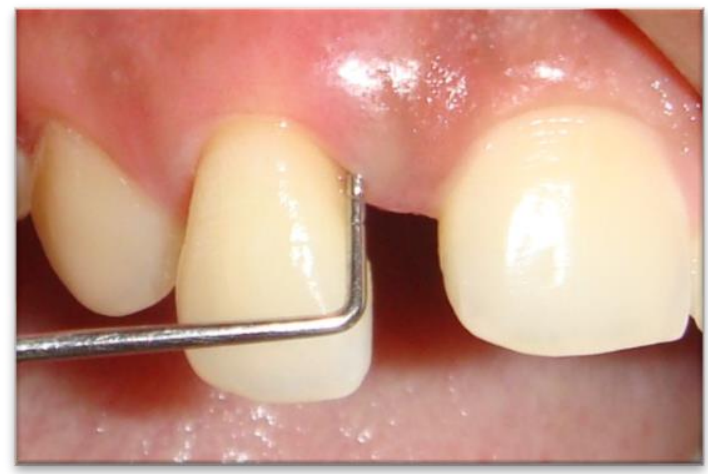

Fig. 4: Probing Pocket Depth WRT 12 Is 8 mm.

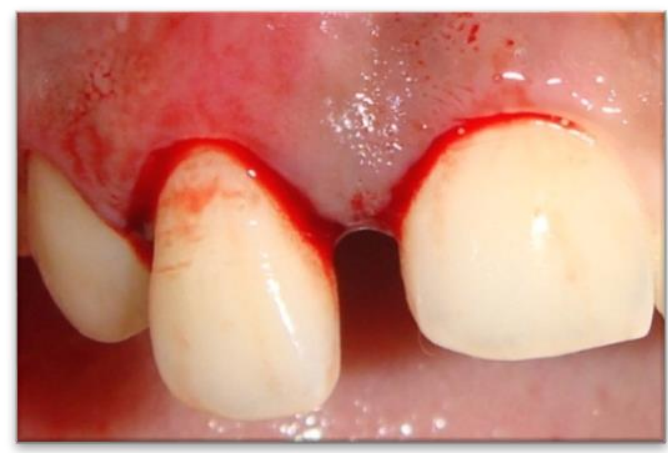

Fig. 5: Crevicular Incisions Given.

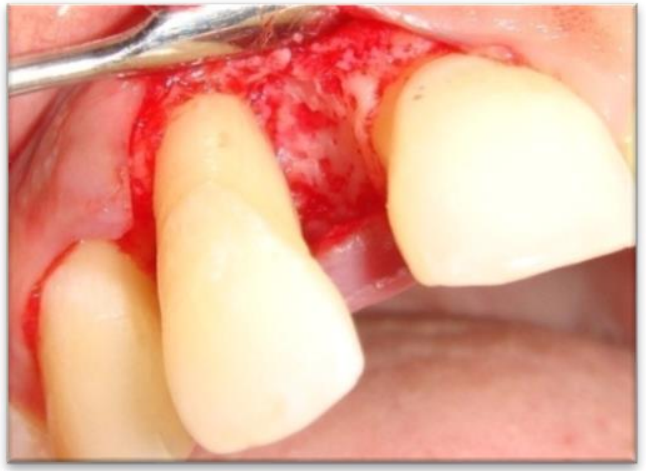

Fig. 6: Full Thickness Mucoperiosteal Flap Reflected.

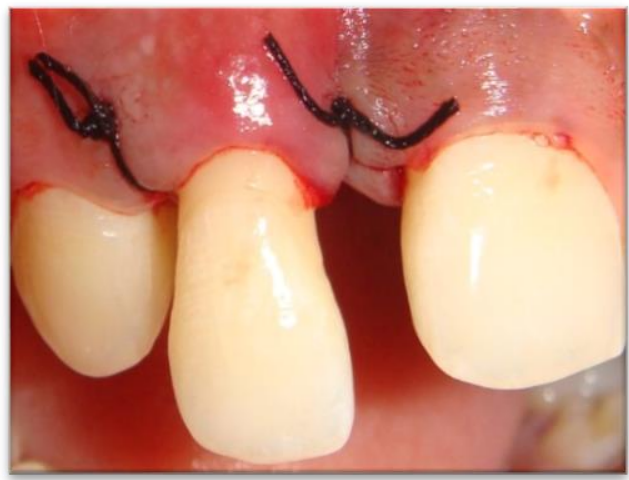

Fig. 7: Sutures Placed. 


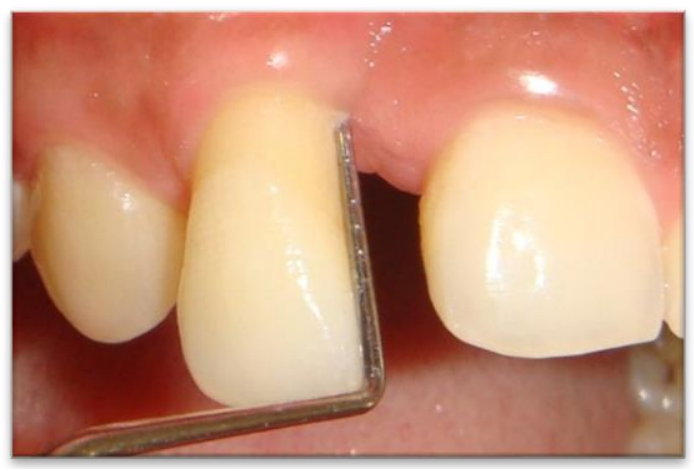

Fig. 8: Probing Pocket Depth Reduced to $4 \mathrm{~mm} 6$ Months after Flap Surgery.

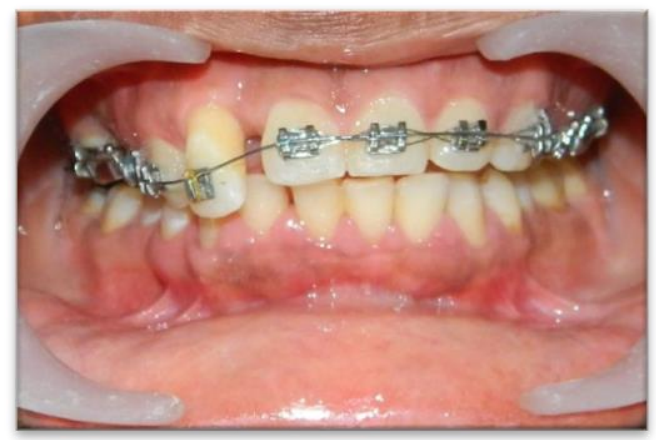

Fig. 9: Levelling and Alignment of Upper Teeth.

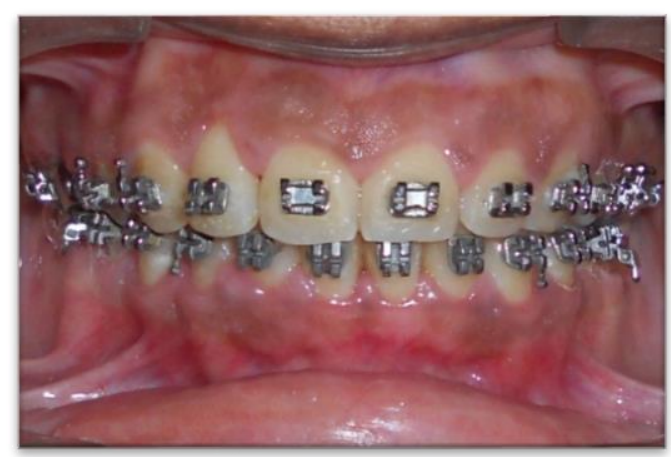

Fig. 10: Space Closure.

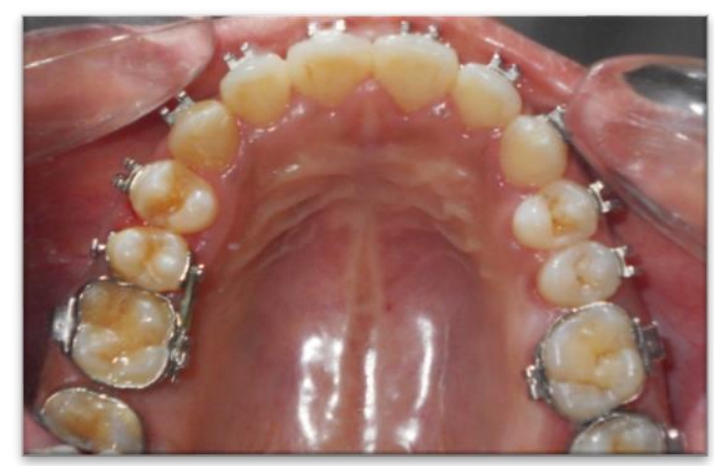

Fig. 11: Correction of Cross Bite WRT 15.

A non-extraction orthodontic therapy was planned. Initially, leveling and alignment of 12 was done followed by space closure in the maxillary arch. A pre-adjusted edgewise appliance was planned. Light orthodontic forces were applied to intrude 12 . Once space closure was achieved, torquing of the root with respect to 12 was done to improve the retention. The orthodontic treatment extended over a period of two years during which the patient was recalled on regular intervals for check-up. (Figure 9-11)

\section{Orthodontic therapy}

At the end of two years, extruded 12 was aligned so that it follows the proper arch contour, 15 that was in cross bite was corrected, and space between 11, 12 and 23, 24 was closed. A permanent lingual retainer was given to the patient. (Figure 12-13)

\section{Completion of treatment}
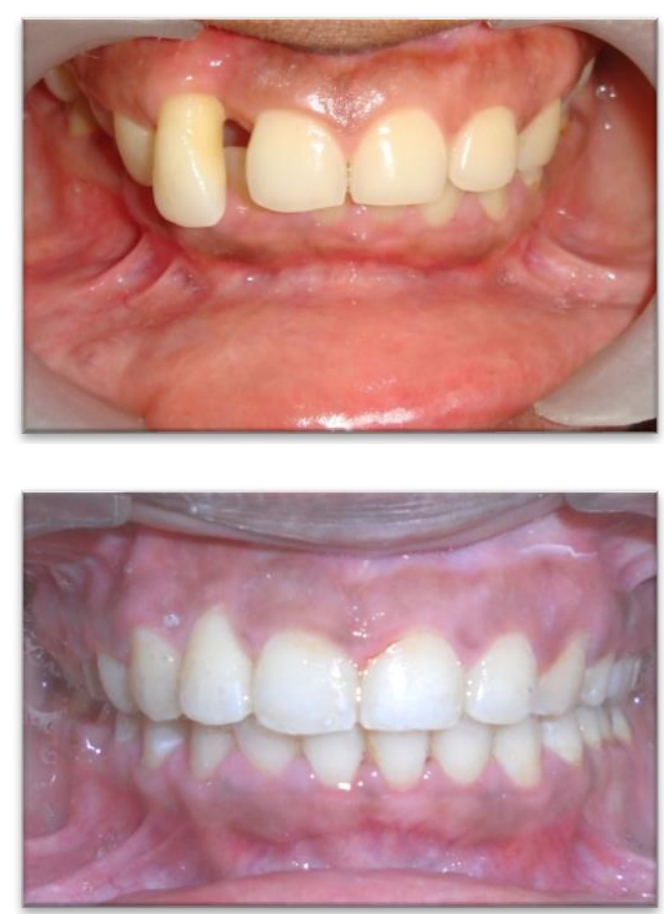

Fig. 12: Extruded 12 Is Intruded, Aligned and Space Is Closed B/N 12 and 11.
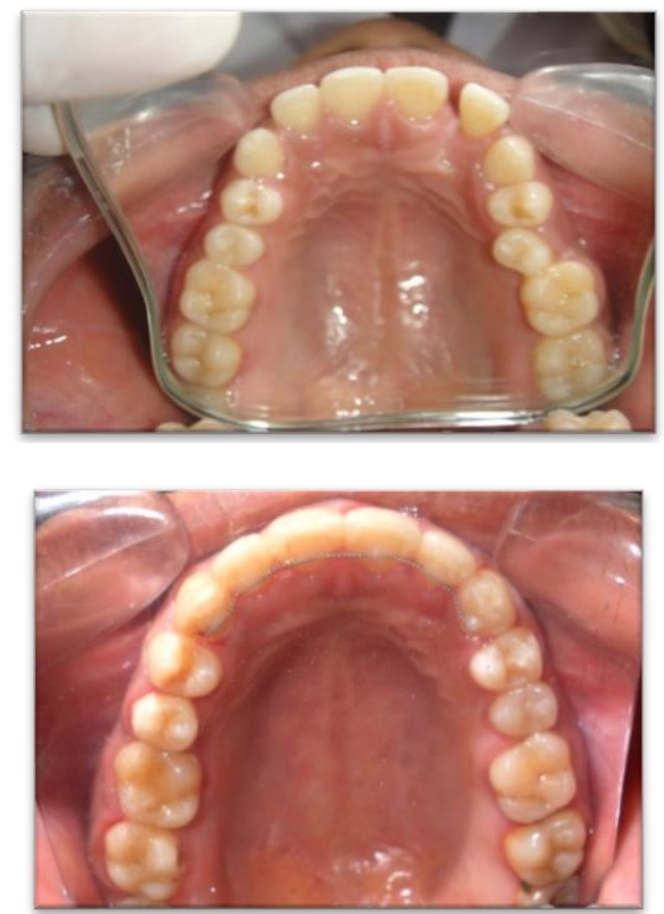

Fig. 13: Cross Bite WRT 15 Corrected and Fixed Lingual Retainer Placed.

\section{Discussion}

Age is no longer a contraindication for orthodontic treatment. However, for a successful orthodontic therapy, the periodontal 
status should be considered before and after the commencement of treatment. Periodontal health is essential for any form of dental treatment. Majority of adult orthodontic patients manifest with a coexisting periodontal pathology resulting in pathologic migration, spacing, flared incisors and trauma from occlusion. It is of paramount importance to control the existing periodontal disease before initiating comprehensive orthodontics. Hence, an interdisciplinary approach is required to obtain functional and esthetic dentition. [7] (Riberal MBC et al. 1999, p. 979).

Periodontitis appears to be a major factor in bone destruction around the teeth which can cause pathological tooth migration.[8] (Towfighi PP \& Brunsvold MA 1997, p. 967).

In the present case 12 had migrated because of severe bone loss that resulted in extrusion of the tooth, thus compromising esthetics. Hence periodontal treatment was initially done to control the inflammation so that the tooth can be subjected to orthodontic forces without further compromising periodontal status.[9] (Wankhede AN et al. 2014, p. 153).

Once desired results are obtained it is of paramount importance the patient is recalled at regular intervals for check-up. Supportive periodontal therapy is important in maintaining the health and integrity of teeth and supporting tissues. [10] (Ong MA et al. 1998, p. 271).

\section{Conclusion}

Ultimately, it is not only the beauty of the structure, but the foundation that will stand the test of time. The interrelationship between orthodontics and periodontics is often symbiotic and interdependent. Thus co-operation between different specialties in dentistry is extremely important in establishing diagnosis as well as in treatment planning.

Where more than one reference is being cited in the same pair of brackets the reference should be separated by a comma; authors and dates should not be separated by a comma, thus (Smith 1970 , Jones 1980). Where there are two authors being cited in brackets then they should be joined by an ' $\&$ ', thus (Smith \& Jones 1975).

When a paper is cited, the reference list should include authors' surnames and initials, date of publication, title of paper, name of journal in full (not abbreviated), volume number, and first and last page numbers. Example: Watson R, Hoogbruin AL, Rumeu C, Beunza M, Barbarin B, MacDonald J \& McReady T (2003) Differences and similarities in the perception of caring between Spanish and United Kingdom nurses. Journal of Clinical Nursing $12,85-92$.

When a book is cited, the title should be stated, followed by the publisher and town, county/state (and country if necessary) of publication. Example: Smith GD \& Watson R (2004) Gastroenterology for Nurses. Blackwell Science, Oxford. Where the reference relates to a chapter in an edited book, details of author and editors should be given as well as publisher, place of publication, and first and last page numbers. Example: Chalmers KI (1994) Searching for health needs: the work of health visiting. In Research and its Application (Smith JP ed.), Blackwell Science, Oxford, pp. 143-165.

The edition (where appropriate) of all books should be identified, e.g. 2nd edn. References stated as being 'in press' must have been accepted for publication and a letter of proof from the relevant journal must accompany the final accepted manuscript. Please provide access details for online references where possible: Example: Lynaugh JE (1997) The International Council of Nurses is Almost 100 years old. University of Pennsylvania, PA. Available at: http://www.nursing.upenn.edu/history/Chronicle/F97/icn.htm (accessed 12 December 2002). The reference list should be prepared on a separate sheet and be in alphabetical order and chronological order by first authors' surnames.

Website references should include the most recent date of access. Example: Centers for Medicare \& Medicaid Services, U.S. Department of Health and Human Services. CMS proposals to im- plement certain disclosure provisions of the Affordable Care Act. Available at:

http://www.cms.gov/apps/media/press/factsheet.asp?Counter=422 1. Accessed January 30, 2012.

Personal communications and unpublished data should be cited in the body of the paper in parentheses, not listed in the references section. Manuscripts that have been accepted for publication may be listed as "in press" with DOI if available; manuscripts that have been submitted or are under revision but have not been accepted may not be cited as references.

\section{A step before the final submission}

Detailed submission guidelines can be found on the journal web pages. All authors are responsible for understanding these guidelines before submitting their manuscript.

\section{Conclusion}

In this section you should present the conclusion of the paper. Conclusions must focus on the novelty and exceptional results you acquired. Allow a sufficient space in the article for conclusions. Do not repeat the contents of Introduction or the Abstract. Focus on the essential things of your article.

\section{Acknowledgement}

This is a text of acknowledgements. Do not forget people who have assisted you on your work. Do not exaggerate with thanks. If your work has been paid by a Grant, mention the Grant name and number here.

\section{References}

[1] Ngom PI, Diagne F, Benoist HM \& Thiam F (2006), Intraarch and interarch relationships of the anterior teeth and periodontal conditions. Angle Orthod 76, 236-242.

[2] Lt Col M Panwar, Col B Jayan, Col VB Mandlik \& Lt Col AK Jha (2010) Combined Periodontal and Orthodontic Treatment of Pathologic Migration of Anterior Teeth. MJAFI 66, 67-69.

[3] Helm S \& Petersen PE (1989), Causal relation between malocclusion and periodontal health. Acta Odontol Scand 47, 223-228. http://dx.doi.org/10.3109/00016358909007705.

[4] Kokich VG (2009), Adjunctive role of orthodontic therapy, In: Newman MG, Takei HH, Carranza FA. Carranza's Clinical periodontology, $10^{\text {th }}$ edition, Saunders Elsevier, 856-870.

[5] Martinez-Canut P\& Carrasquer A (1997), A study on factors associated with pathologic tooth migration. J Clin Periodontol 24, 492497. http://dx.doi.org/10.1111/j.1600-051X.1997.tb00217.x.

[6] Kalia S \& Melsen B (2001), Interdisciplinary approaches to adult orthodontic care. $J$ of Orthodontics 28, 191-196. http://dx.doi.org/10.1093/ortho/28.3.191.

[7] Riberal MBC, Bolognese AM \& Feres EJ (1999), A Periodontal evaluation after orthodontic treatment. J Dent Res 78, 979-984.

[8] Towfighi PP \& Brunsvold MA (1997), Pathologic migration of anterior teeth in patients with moderate to severe periodontitis. $J \mathrm{Per}$ iodontol 68, 967-972. http://dx.doi.org/10.1902/jop.1997.68.10.967.

[9] Wankhede AN, Bhutada GP, Sayed AJ, Gattani DR (2014), Repositioning of pathological migrated teeth following periodontal surgery in chronic periodontitis. Int $J$ of Healthcare and Biomedical Res 2, 153-156.

[10] Ong MA, Wang HL \& Smith FN (1998), Interrelationship between periodontics and adult orthodontics. J Clin Periodontol 25, 271-272. http://dx.doi.org/10.1111/j.1600-051X.1998.tb02440.x. 